\title{
O papel dos arquivos das instituições federais de ensino superior e a experiência do Arquivo Central da
}

\author{
Universidade de Brasília
}

\author{
Cynthia Roncaglio \\ roncaglio@unb.br \\ Universidade de Brasília, Faculdade de Ciência da Informação, Brasília, DF, Brasil
}

Resumo: As Instituições Federais de Ensino Superior no Brasil, assim como outras instituições da administração pública, são detentoras de arquivos formados em decorrência das suas atividades - no caso das IFES, atividades administrativas e acadêmicas decorrentes das suas funções finalísticas: ensino, pesquisa e extensão. Ao longo da sua existência as IFES adotaram procedimentos diversos de organização e tratamento dos documentos arquivísticos, não necessariamente baseados em conhecimentos técnico-científicos da Arquivologia. Isto, em parte, porque a legislação arquivística, que estabelece uma série de normativas sobre o assunto, teve início apenas nos anos 1990. Recentemente, percebe-se a influência crescente da Arquivologia na (re)estruturação dos arquivos das IFES e o estabelecimento de normativas federais próprias para os arquivos de universidades. Tal fenômeno tem a ver, em certa medida, com o Programa de Apoio ao Plano de Reestruturação e Expansão das Universidades (REUNI), - com a consequente expansão dos cursos de Arquivologia no país e contratação de arquivistas para atuar nas instituições universitárias e também com a Lei de Acesso à Informação de 2011. Este artigo visa a descrever algumas dessas transformações e apresentar a experiência do Arquivo Central (ACE) da Universidade de Brasília (UnB) referente às estratégias de visibilidade e sensibilização da comunidade universitária para a importância dos arquivos para a administração, ensino, pesquisa e extensão.

Palavras-chave: Arquivologia; arquivos de universidades; Brasil; instituições federais de ensino superior; legislação arquivística; Universidade de Brasília.

El papel de los archivos de las instituciones federales de enseñanza superior y la experiencia del Archivo Central de la Universidad de Brasilia

Resumen: Las Instituciones Superiores Federales de Educación (IFES) y otras instituciones de la administración pública, en Brasil, son responsables de los archivos formados como resultado de sus actividades; en el caso de las IFES, además de las actividades administrativas, los archivos custodian documentos resultantes de las actividades académicas derivadas de sus funciones esenciales: docencia, investigación y extensión. Durante su existencia, las IFES adoptaron diversos procedimientos para la organización y tratamiento de los documentos, no necesariamente fundamentados en las concepciones teórico-prácticas de la Archivística. Esta situación, en parte, fue una de las consecuencias de la ausencia, por muchos años, de legislación archivística en el país; las normativas legales sobre esta disciplina surgen, sólo, en la década de 1990. En los últimos años, se observa una progresiva influencia de los preceptos archivísticos en la re-estructuración de los archivos de las IFES así como la adopción y el establecimiento de las regulaciones federales en relación a los archivos universitarios. Este fenómeno está vinculado, principalmente, a la creación del Programa de Apoyo al Plan de Reorganización y Expansión de las Universidades (REUNI) y la consiguiente expansión de los cursos de Archivística por todo el país, lo que trajo consigo la contratación de archiveros para trabajar en las universidades; la Ley de Acceso a la Información de 2011, también, ha sido un factor determinante en las nuevas dinámicas de organización y funcionamiento de los archivos universitarios brasileños. Este artículo tiene como 
objetivo describir algunos de estas transformaciones y presentar, además, la experiencia del Archivo Central (ACE) de la Universidad de Brasilia (UnB) relacionada con las estrategias de visibilidad y sensibilidad realizadas en la comunidad universitaria para demostrar la importancia del archivo en la gestión, la enseñanza, la investigación y la extensión de la universidad.

Palabras-clave: archivos de las universidades; Archivística; archiveros; Brasil; instituciones federales de enseñanza superior; legislación archivística; Universidad de Brasilia.

The role of archives of the federal institutions of higher education and the experience of the Central Archive of the University of Brasilia

Abstract: The federal institutions of higher education (IFES) in Brazil, as well as other institutions of public administration, they hold files because of their activities - In the case of IFES, in addition to administrative activities also teaching, research and extension. Throughout its existence, the IFES adopted various procedures of organization and handling of archival documents do not necessarily based on technical and scientific knowledge of Archival. Archival legislation aimed at establishing regulations on the subject, only began in the 1990s. Recently, we can see the growing influence of Archives Administration in (re) structuring of the IFES files and establishing its own federal regulations for universities files. This phenomenon has to do, to some extent, with the Program of Support to the a Plan of Reorganization and Expansion of Universities (REUNI) - with the consequent expansion of archives administration courses in the country and to hire archivists to work in universities and also with the Access to Information Act, created in 2011. This paper aims to describe some of these changes and present the experience of the Central Archives (ACE) at the University of Brasilia (UnB) referring to the visibility and awareness strategies of the university community to the importance of archives for the administration, teaching, research and extension.

Keywords: Archives Administration; archivists; Brazil; federal institutions of higher education; Archival legislation. University archives; University of Brasília. 


\section{Introdução}

As Instituições Federais de Ensino Superior (IFES) do Brasil, tal como outras instituições da administração pública, são detentoras de arquivos formados em decorrência das suas atividades. No caso das IFES, atividades administrativas e acadêmicas decorrentes das atividades finalísticas da instituição, a saber, ensino, pesquisa e extensão. Ao longo da sua existência as IFES adotaram procedimentos diversos de organização e tratamento dos documentos arquivísticos, não necessariamente baseados em conhecimentos técnicocientíficos da Arquivologia. A legislação arquivística, que estabelece uma série de normativas sobre o assunto, teve início apenas nos anos 1990.

Recentemente percebe-se maior influência da Arquivologia, enquanto disciplina científica, na (re)estruturação dos arquivos das IFES, assim como o estabelecimento de normativas federais próprias para esses arquivos. Tal fenômeno tem a ver, em certa medida, com diferentes fatos que vem ocorrendo neste início do século XXI: o Programa de Apoio ao Plano de Reestruturação e Expansão das Universidades (REUNI) e a consequente expansão dos cursos de Arquivologia no país, a contratação de arquivistas para atuar nas instituições universitárias e, também, a criação da Lei de Acesso à Informação, em 2011.

Este artigo apresenta um breve contexto histórico da criação das universidades públicas no Brasil, em especial das universidades federais, descreve algumas das transformações mais recentes pelas quais as IFES estão passando e apresenta a experiência do Arquivo Central (ACE) da Universidade de Brasília (UnB) referente às estratégias de visibilidade e sensibilização da comunidade universitária quanto à importância dos arquivos para a administração, o ensino, a pesquisa e extensão.

\section{Breve Contexto Histórico da Criação das Universidades Brasileiras}

A ideia de criar instituições públicas universitárias no Brasil sofreu enorme resistência dos portugueses e da própria elite brasileira, tanto no período colonial (1530-1822) quanto no imperial (1822-1889). Várias tentativas foram feitas no período colonial: dos jesuítas, no século $X V I$, passando pelos inconfidentes no século XVIII e quando da transferência da sede da Monarquia para o Brasil. Mas tanto por parte do governo português quanto por parte de brasileiros, continuava a se considerar mais adequado para a elite local buscar aprimorar seus estudos na Universidade de Coimbra e em outras universidades europeias. Segundo Fávero, "todos os esforços de criação de universidades, nos períodos colonial e monárquico, foram malogrados, o que denota uma política de controle por parte da Metrópole de qualquer 
iniciativa que vislumbrasse sinais de independência cultural e política da Colônia." (FÁVERO, 2000, p. 19).

No Império surgiram outras tentativas malogradas de criação de universidades; uma delas, apresentada pelo próprio Imperador em seu último discurso (1889), propunha a criação de uma universidade no Norte e outra no Sul do país, que poderiam se constituir em centros de alta organização científica e literária. Proclamada a República, em novembro de 1889, outras tentativas foram feitas. Na Constituição de 1891, o ensino superior foi considerado atribuição do Poder Central, mas não exclusivamente. No período entre 1889 e a Revolução de 1930, o ensino superior no Brasil sofreu várias alterações em decorrência da promulgação de diferentes dispositivos legais (FÁVERO, 2000, p. 21). Ainda Segundo Fávero, “embora o surgimento da universidade, apoiado em ato do Governo Federal, continuasse sendo postergado, o regime de "desoficialização" do ensino acabou por gerar condições para o surgimento de universidades, tendendo o movimento a deslocar-se provisoriamente da órbita do Governo Federal para a dos Estados" (FÁVERO, 2006, p.21).

Nesse contexto surgem no início do século XX três universidades como instituições livres: Universidade de Manaus (1909); Universidade de São Paulo (1911) e Universidade do Paraná (1912), apoiadas pela sociedade e pelo poder político local, cientes da necessidade de qualificação profissional para impulsionar o desenvolvimento socioeconômico dos seus estados. Grosso modo, os principais cursos criados nessas instituições foram os cursos de Medicina, Direito e Engenharia. Mais tarde essas universidades, que passaram por várias reformulações administrativas e jurídicas, disputariam seu lugar na história como primeiras universidades do Brasil. Todavia, de fato, a primeira instituição universitária, criada legalmente pelo Governo Federal, é a Universidade do Rio de Janeiro, em 1920, quando são reunidas as escolas Politécnica e de Medicina e a Faculdade Livre de Direito, com autonomia acadêmica e administrativa. Cercada de muitas polêmicas e controvérsias, a criação da Universidade do Rio de Janeiro, de acordo com Fávero, serviu para intensificar o debate no país em torno de questões importantes, e ainda atuais, tais como concepção de universidade, quais são as suas funções, autonomia universitária e modelo de universidade a ser adotado no Brasil (FÁVERO, 2006, p.22).

De qualquer modo as universidades públicas federais demorariam ainda a se estruturar e consolidar, dentre outros motivos porque, de acordo com Ortiz:

O Brasil do início do século $[X X]$ é um país agrário e não integrado nacionalmente. Dificilmente poderíamos caracterizá-lo como sendo uma 'nação', isto é, uma sociedade moderna integrada dentro de uma totalidade coerente. O país não havia ainda conhecido sua revolução industrial, e os 
traços de uma sociedade escravocrata não eram meras reminiscências, mas elementos vivos do presente. O território nacional, longe de se constituir numa unidade geográfico-cultural, a rigor, seria mais bem compreendido como sendo um arquipélago de práticas sociais, interesses e poderes. (ORTIZ, 2001, p.186).

Assim, lentamente, porém, num ritmo crescente, foram sendo criadas novas universidades públicas no Brasil. Após a criação da Universidade do Rio de Janeiro, depois transformada em Universidade do Brasil em 1937, surgiram a Universidade de Minas Gerais (1927), federalizada em 1949, e a Universidade do Rio Grande do Sul (1934), federalizada em 1950. Timidamente, a partir dos anos 1940, mas acentuadamente nos primeiros anos de 1960, são criadas mais 20 universidades, período que coincide com a chamada "revolução industrial" (1930-1956), com a fase democrática do Governo Republicano (1945-1964), e com a internacionalização da indústria (1956 em diante), quando são feitos pesados investimentos em produção de bens de capital, após a Segunda Guerra Mundial.

Portanto, pode-se considerar o período de 1945 a 1964 como o período da efetiva implantação do ensino público federal brasileiro (VENÂNCIO, 2012, p.41). Como constata Venâncio (2012), no período do Regime Militar (1964-1985), a média de implantação de universidades federais caiu pela metade, apesar do propalado investimento da Ditadura Militar em ciência e tecnologia.

Nos anos 1990, com a Reforma Administrativa do Estado, o ensino superior volta a ser foco do debate, mas a proposta de interferência mínima do Estado provoca a expansão das universidades particulares em detrimento das universidades públicas. ${ }^{1}$

No final dos anos 1990 e início dos anos 2000, segundo, Relatório do MEC (2012),

a elitização do acesso à educação superior passou a ser fortemente questionada e apontada como uma das formas de exclusão social. Percebeu-se então que a superação dessa situação discriminatória somente ocorreria por meio da ampliação das oportunidades de acesso à educação superior. (MEC, 2012, p.9).

Assim, para atender o disposto na Constituição, em 2001 foi elaborado o Plano Nacional de Educação - PNE (2001-2010), estabelecendo metas que exigiam aumento dos investimentos nessa área e buscavam a ampliação do número de estudantes atendidos em todos os níveis da educação superior.

Nesse contexto foram também estabelecidos programas de expansão do ensino superior federal, cuja primeira fase, denominada de Expansão I, compreendeu o período de

\footnotetext{
${ }^{1}$ Para maiores detalhes sobre este período ver, dentre outros, os artigos de MARTINS (2000) e ALVES (2011). RICI: R.Ibero-amer. Ci. Inf., ISSN 1983-5213, Brasília, v. 9, n. 1, p. 178-194, jan./jun.2016.
} 
2003 a 2007 e teve como principal meta interiorizar o ensino superior público federal, o qual contava até o ano de 2002 com 45 universidades federais e 148 campi/unidades (MEC, 2012, p.9).

No segundo momento, a partir de 2007, foi lançado o Programa de Apoio aos Planos de Reestruturação e Expansão das Universidades Federais (REUNI). Dentre os seus principais objetivos, o REUNI visa a prover as universidades públicas federais das condições necessárias para ampliação do acesso e permanência na educação superior. Esse Programa prevê metas para ampliação das estruturas físicas, reforço e ampliação das iniciativas para ampliação de vagas e elevação da qualidade da educação nacional (REUNI, 2007). Hoje, em 2014, temos 67 universidades federais em todo o Brasil, além de numerosos centros universitários, institutos, faculdades e escolas. ${ }^{2}$

Embora sejam muitos os desafios decorrentes da trajetória do ensino superior no Brasil, em especial a configuração das universidades públicas federais no cenário educacional e as mútuas influências e diferentes interações com a sociedade brasileira, é notório que a constituição dos arquivos no âmbito dessas instituições e a atuação do arquivista, só podem ser pensadas em estreita vinculação com a criação dos próprios cursos de graduação em Arquivologia. Até o momento, a maioria dos cursos de graduação em Arquivologia foi criada no âmbito das universidades públicas federais, como evidenciaremos adiante.

\section{Como Se Originam os Arquivos das Instituições Federais de Ensino Superior no Brasil?}

Ora, a resposta a esta pergunta parece óbvia. Afinal, como tantos outros órgãos públicos, os arquivos das universidades se originam quando as universidades são criadas e começam a desenvolver suas atividades, isto é, a gerar documentos para informar, resolver, estabelecer, provar, comprovar, atestar suas ações e relações. Sim, esta pode ser a resposta, se limitarmos o uso da palavra "arquivos" aos documentos gerados organicamente no decorrer das atividades realizadas pela instituição. Porém, se usarmos "arquivos" num sentido mais amplo, compreendendo uma estrutura física, administrativa, com atribuições e

\footnotetext{
${ }^{2}$ Segundo o Ministério da Educação considera-se universidades as instituições cujas atividades-fim são o ensino, a pesquisa e a extensão em todas as áreas do conhecimento humano; centros universitários - instituições de ensino em todas as áreas do conhecimento humano, não sendo obrigadas a desenvolver pesquisas; institutos - instituições de ensino e pesquisa que não cobrem todas as áreas do conhecimento humano; faculdades integradas - instituições de ensino com propostas curriculares em mais de uma área do conhecimento, organizadas sob o mesmo comando e regimento comum, não sendo obrigadas a desenvolver pesquisas; faculdades - são instituições de ensino que não cobrem todas as áreas do conhecimento humano e não são obrigadas a desenvolver pesquisas; escolas são instituições que oferecem um ou mais cursos de graduação em uma área específica, não precisando fazer pesquisa. Disponível:<http://pt.wikipedia.org/wiki/Anexo:Lista_de_institui\%C3\%A7\%C3\%B5es_de_ensino_superior_do_Brasil >. Acesso em: 20 mai. 2014. 
competências definidas para custodiar os documentos de arquivo, dotada de um quadro pessoal, com cargos e salários e orçamento anual, aí teremos uma resposta menos óbvia e mais obtusa.

Embora existam muitas faculdades e universidades antigas no Brasil, instituídas gradativamente desde o final do século XIX, como visto antes, pouco se sabe sobre a organização de seus arquivos, na sua acepção mais ampla, ao longo do tempo. Quando foram instalados? Como funcionavam e funcionam hoje? Quem eram/são os responsáveis pela organização dos documentos? Que métodos adotavam/adotam para organizar e recuperar as informações? Quais documentos foram/são preservados? O seu acesso era/é irrestrito? Em que condições? Sob quais critérios? Há como recuperar documentos que auxiliem na construção da história da própria universidade? Há conjuntos documentais que permitam recuperar a história da ciência no Brasil?

No âmbito da produção científica na área de Arquivologia, talvez não com a mesma abrangência ou perspectiva histórica, mas com finalidades semelhantes, tais perguntas vêm sendo feitas há algum tempo. Fazendo uma breve pesquisa em bancos de teses e dissertações, encontramos indícios de pesquisas que buscam, desde os anos 1990, de um modo ou de outro, responder a essas questões, ou contribuir para que uma parte delas seja respondida ${ }^{3}$. No âmbito da comunicação científica, sabe-se que, em 1992, ocorreu o I Seminário Nacional de Arquivos Universitários, a partir do qual foram publicados 26 artigos com temáticas que abrangiam política nacional de arquivos, sistema de arquivos universitários, arquivos e centros de documentação em universidades, contribuição dos arquivos para a pesquisa científica, entre outros (BOTTINO, 1998, p. 75).

Dezessete anos depois, na abertura do Seminário Nacional de Arquivos Universitários e de Instituições de Pesquisa e Ciência, no âmbito do XV Congresso Brasileiro de Arquivologia, promovido pela Coordenadoria do Sistema de Arquivos da Universidade Estadual de Campinas, Neire do Rossio Martins (2008), relembra que como resultado daquele Seminário de 1991, entre outras iniciativas, previu-se a criação de um Comitê de Arquivos Universitários no âmbito

3 Embora sejam poucos os trabalhos encontrados há alguns bastante significativos. BOTTINO, M. Arquivo universitário: considerações em torno da questão: panorama da situação no Brasil. Rio de Janeiro, 1994, 203 f. Dissertação (Mestrado em Ciência da Informação), Universidade Federal do Rio de Janeiro/instituto Brasileiro em Informação em Ciência e Tecnologia. CÔRTES, Maria R. P. A. Arquivo Público e informação: acesso à informação nos arquivos públicos do Brasil. Belo Horizonte, 1996. Dissertação (Mestrado em Ciência da Informação) Universidade Federal de Minas Gerais.

MORENO, N. A. A informação arquivística no processo de tomada de decisão em organizações universitárias. 2006. 220f. Tese (Doutorado em Ciência da Informação) - Escola de Ciência da Informação, Universidade Federal de Minas Gerais, Belo Horizonte. Disponível em: <http://dspace.lcc.ufmg.br>. Acesso em: 20 mai.2014. 
da Associação dos Arquivistas Brasileiros $(A A B)$ e a realização de outros seminários do gênero no Congresso Brasileiro de Arquivologia. Ainda segundo Martins (2008), ambas as recomendações foram acatadas pela $A A B$ na época, mas, depois, ocorreu uma descontinuidade na realização dos seminários e no funcionamento do Comitê.

Em 1999, a Comissão Permanente de Avaliação de Documentos da Universidade Federal da Paraíba - CPAD/UFPB encaminhou ao Arquivo Nacional a 1a versão de uma Tabela de Temporalidade e Destinação de Documentos de Arquivo relativos às suas atividades-fim. Tal iniciativa levou o Arquivo Nacional, em 2006, a realizar o I Workshop com as Instituições Federais de Ensino Superior - IFES, cujo tema central era Classificação, Temporalidade e Destinação de Documentos de Arquivo relativos às atividades-fim. A partir deste evento, constituiu-se um Grupo de Trabalho (GT), no âmbito do Sistema de Gestão de Documentos de Arquivo (SIGA), da administração pública federal, denominado GT-IFES-AN, coordenado pela Coordenação-Geral de Gestão de Documentos do Arquivo Nacional - COGED/AN e integrado por técnicos do Arquivo Nacional e por representantes de diversas instituições de ensino superior. As reuniões técnicas do GT-IFES-AN culminaram na criação da Portaria no92, de 23 de setembro de 2011, do Arquivo Nacional do Brasil, que aprovou o Código de Classificação e a Tabela de Temporalidade e Destinação de Documentos de Arquivo relativos às Atividades-Fim das Instituições Federais de Ensino Superior (IFES).

Quanto a uma perspectiva histórica dos arquivos universitários, Venâncio (2012) esboça uma cronologia de como teriam se organizado os arquivos e os arquivistas nas universidades brasileiras, utilizando como fontes, sobretudo, a legislação federal disponível no Portal da Câmara dos Deputados do Congresso Nacional. No período de 1920 a 1937, quando da implantação das primeiras universidades, o autor encontrou poucas informações sobre a organização dos arquivos e constatou que a solução usual para cuidar dos arquivos cabia aos porteiros e amanuenses (escriturários encarregados de registrar ou copiar documentos), que exerciam as funções de "receber, expedir e classificar documentos administrativos, assim como aqueles referentes às atividades finalísticas das instituições de ensino superior" (VENÂNCIO, 2012, p.44).

Na década de 1930 percebe-se algumas modificações no âmbito das próprias universidades que passam a definir, nos seus regulamentos, a adoção de procedimentos arquivísticos, bem como a legislação federal passa a prever a contratação de arquivistas ou ajudantes de arquivistas. Venâncio observa que neste período ocorre não só uma distinção das atividades de porteiros, amanuenses e arquivistas, mas a percepção salarial para cada um deles é diferente, com maior vantagem para os arquivistas - o que o autor considera 
surpreendente, posto que o ensino de Arquivologia ainda era bastante incipiente, com apenas alguns cursos oferecidos pelo Arquivo Nacional (VENÂNCIO, 2012, p.44-45).

Entre 1938 e 1960, os arquivos universitários e os arquivistas são beneficiados pela implantação da racionalidade burocrático-administrativa no governo Federal e, principalmente, pela criação do Departamento Administrativo do Serviço Público (DASP) que, dentre outros aspectos, reconhecia a importância dos serviços dos arquivos e das bibliotecas para a administração pública. Portanto, a lei recomendava a ampliação do quadro de arquivistas nas universidades federais e verbas para funcionamento das atividades. No entanto, tal situação não duraria muito. Entre 1961 e 1991, Venâncio define como o período de "crise e renovação". Segundo o autor, nesse período é cada vez mais raro encontrar na legislação federal referência aos arquivos e aos arquivistas no âmbito das universidades. No entanto, no mesmo período, crescem as referências aos cursos de Biblioteconomia (na década de 1950 já existiam 6 cursos, além do tradicional curso da Biblioteca Nacional), eventos na área e consolidação de estudos dos bibliotecários na área de documentação, o que pode explicar em parte, segundo o autor, a descontinuidades dos serviços arquivísticos nas universidades. Tal situação só mudará, ainda que lentamente, a partir da criação da Lei de Arquivos, de 1991 (VENÂNCIO, 2012, p. 50-52).

Além da criação da Lei Federal no 8.159/1991, vários outros fatores contribuíram para a retomada, sempre lenta, da organização dos arquivos das universidades, dentre eles, a criação dos cursos de Arquivologias nas IFES e nas universidades estaduais, desde a década de $1970^{4}$, a criação da Associação dos Arquivistas Brasileiros, em 1971, com o objetivo de "dignificar a profissão de Arquivista e contribuir para o desenvolvimento da Arquivologia Brasileira". ${ }^{5}$

No entanto, decisões mais recentes que vêm sendo tomadas no âmbito do Governo Federal demonstram mudanças significativas nas universidades. Uma delas como já foi dito, foi a implementação do REUNI e, consequentemente, a criação de novos cursos de Arquivologia ${ }^{6}$, a admissão de arquivistas nas universidades e, consequentemente, novas perspectivas de

4 Foram criados três cursos de Arquivologia na década de 1970: Universidade Federal do Estado do Rio de Janeiro (UNIRIO) (1976); Universidade Federal de Santa Maria (UFSM) (1976); e Universidade Federal Fluminense (UFF) (1978).

5 Associação dos Arquivistas Brasileiros. Disponível em: <http://www.aab.org.br/index.php?option=com_content\&view=article\&id=61:aab\&catid=30>. Acesso em: 27 set.2014.

6 Na década de 1990 foram criados mais cinco cursos de Arquivologia nas seguintes universidades: Universidade de Brasília (UnB) (1990); Universidade Estadual de Londrina (UEL) (1997); Universidade Federal da Bahia (UFBA) (1997); Universidade Federal do Rio Grande do Sul (UFRGS) (1999). Universidade Federal do Espírito Santo (UFES), em 1999. RICI: R.Ibero-amer. Ci. Inf., ISSN 1983-5213, Brasília, v. 9, n. 1, p. 178-194, jan./jun.2016. 
intervenção nos documentos, novos olhares sobre as funções e o sentido dos arquivos. Ao mesmo tempo, a ampliação de estruturas físicas e de vagas motivadas pelo Reuni também criaram um aumento da produção documental administrativa e científica.

Outro dispositivo importante, referente a todos os órgãos da administração pública foi a promulgação da Lei de Acesso à Informação (LAI), no 12.527, de 18 de novembro de 2011, que dispõe sobre os procedimentos a fim de garantir o acesso a informações. A LAI reforça a necessidade e a urgência de se organizar, tratar e disponibilizar as informações contidas nos arquivos de todas as instituições públicas.

Nesse contexto, as IFES, nem sempre atentas ao seu papel de gestoras e guardiãs dos documentos públicos são compelidas, cada vez mais, a assumir seus deveres e atender aos preceitos legais e técnicos que garantam a preservação e o acesso aos documentos de caráter probatório, informativo e histórico que são patrimônio de toda a sociedade - e não somente da instituição que a constituiu.

Assim, faz-se cada vez mais necessário realizar estudos aprofundados sobre a realidade dos arquivos nas instituições de ensino superior. Isto abrange analisar a estrutura física e administrativa, as representações da comunidade universitária sobre arquivos e arquivistas, a identificação e compreensão das características dos acervos constituídos, suas especificidades e semelhanças em relação a outras instituições públicas e universitárias do Brasil e de outros países, entre tantos outros aspectos.

\section{Para que Servem os Arquivos das Universidades?}

Outra pergunta para qual a resposta parece óbvia. Mas é interessante pensar que as IFES, embora pertencentes ao Poder Executivo Federal, não são órgãos que se assemelham a outros órgãos públicos como ministérios e secretarias. Embora vinculadas ao Ministério da Educação pertencem à administração indireta e perseguem, desde sua criação, a autonomia administrativa, orçamentária e didático-científica na forma da lei e de seus estatutos, evidentemente não sem muitas controvérsias e divergências sobre os limites e os contornos dessa autonomia. Esta é a complexidade do sistema universitário; o fato de que, ao fim e ao cabo, a universidade, como diz Saramago,

é o último nível formativo em que o estudante se pode converter, com plena consciência, em cidadão; é o lugar do debate onde, por definição, o espírito crítico tem de florescer: um lugar de confronto, não uma ilha onde o aluno desembarca para sair com um diploma. (SARAMAGO, 2013, p.26).

Tal conclusão nos parece propícia não somente para estudantes, mas para toda a comunidade universitária, a qual também envolve docentes e técnicos. Embora cada vez mais 
as universidades se pareçam com repartições públicas e tenham sua autonomia contraída, a complexidade da sua missão e dos seus desígnios finalísticos, baseados no tripé ensino, pesquisa e extensão, continuam a produzir conhecimentos e documentos que vão além das exigências de comprovação administrativa, fiscal e legal ou servem de testemunhos das suas atividades acadêmicas e institucionais. As universidades produzem conhecimentos e documentos que dizem respeito à cidade, ao estado, ao país em que estão inseridas e, por vezes, dependendo da escala da pesquisa, ao mundo.

Tal abrangência requer que os arquivos das universidades sejam pensados numa perspectiva mais ampla para que não sirvam somente de apoio à administração universitária e gestão acadêmica, mas que possam ser também um lugar de conhecimento e pesquisa, debruçados sobre a própria produção científica que preservam. Todavia isto ainda está longe de ocorrer. Embora tenhamos ressaltado diversas iniciativas positivas referentes à (re)estruturação dos arquivos de universidades, ainda estamos vendo, em pleno século XXI, várias universidades sem estruturas formais para organizar e preservar os documentos gerados pelas atividades administrativas e acadêmicas, perda de documentos por descaso ou ignorância sobre as leis existentes, desinformação sobre as formalidades que envolvem a produção de documentos públicos, simplificação do uso das tecnologias, perdas irreparáveis em relação aos documentos digitais, bem mais vulneráveis do que os produzidos em papeis.

Contudo precisamos persistir no objetivo de tornar os arquivos vivos, visíveis, atuantes, eficientes e eficazes na resolução dos problemas universitários para que, mais adiante, sejam também ambientes de disseminação e reflexão da produção científica.

\section{Arquivo Central da Universidade de Brasília}

Relatar, ainda que brevemente, a trajetória do arquivo da Universidade de Brasília é descrever, de certa forma, experiências semelhantes a de outras universidades, resguardadas, é claro, as especificidades de cada experiência.

A Universidade de Brasília confunde-se com a história da própria cidade, pois ambas são fundadas quase simultaneamente. Brasília foi inaugurada em 21 de abril de 1960 e a Fundação Universidade de Brasília (FUB), foi criada pela Lei no 3.998, de 15 de dezembro de 1961 e Decreto n-500, de 15 de janeiro de 1962, onde consta o seu estatuto. Segundo Darcy Ribeiro, um dos seus idealizadores e primeiro reitor, a UnB foi criada com a finalidade de estabelecer um centro cultural ímpar, onde não poderia faltar uma universidade para: a) atender uma cidade criada artificialmente no centro do país para ser a capital da República; e b) pensar o Brasil como problema (RIBEIRO, 2012). 
No projeto da estrutura da UnB contemplava-se, além da Biblioteca Central, um “Museu da Civilização Brasileira” e um “Museu da Ciência” (UNIVERSIDADE DE BRASÍLIA, 2012, p. 24). Não há menção no projeto à criação de um Arquivo, talvez por se compreender à época que a responsabilidade e a guarda da documentação coubessem à Biblioteca Central ou aos próprios Institutos e Faculdades. Esta suposição tem apoio, inclusive, no Decreto n-50.732/19961, que cria a Comissão de Planejamento da UnB, da qual Darcy era coordenador geral. Em seu artigo 3으, o Decreto diz o seguinte:

A Comissão instalará, em Brasília, em colaboração com órgãos de administração federal e da Prefeitura, um Centro de Documentação, destinado a atender às necessidades de informação bibliográfica e técnica atualizada dos serviços de assessoramento dos poderes públicos instalados na Capital Federal, e que constituirá o núcleo inicial da Biblioteca Central da Universidade de Brasília. (DECRETO №50.732/1961).

É provável que nos anos seguintes tenha-se tentado instalar, ou existia de fato, um embrião de arquivo nas instâncias administrativas da UnB. Mas os registros encontrados até o momento indicam que somente nos anos 1980, após o período da Ditadura Militar, surgiram circunstâncias favoráveis à criação formal de um arquivo. Ainda assim, parece não ter sido por iniciativa da administração superior, mas por um grupo de docentes e técnicos interessados na restauração e preservação do acervo documental que propuseram a criação do Núcleo de Documentação e Estudos sobre a Universidade de Brasília (NDOC). Tal grupo pretendia criar nesta estrutura inicial um "Setor de Pré-Arquivo", até que fosse implantado o "Arquivo de Custódia Permanente" (CEDOC, 1988).

Após várias negociações foi criado, por meio do Ato da Reitoria n³45, em 25 de agosto de 1986, o Centro de Documentação e Arquivo da Universidade de Brasília (CEDAQ), com atribuições provisórias e sem definição de estrutura formal. Posteriormente, este foi modificado por meio da Resolução do Conselho Diretor no 044, de 28 de novembro de 1988, passando a ser denominado Centro de Documentação (CEDOC), ou seja, passou a não constar o termo "Arquivo" na sua nomenclatura, por ser considerado redundante ${ }^{7}$. As atribuições previstas no Plano Orientador de implantação do CEDOC e que formalmente nunca vieram a existir, contemplavam atividades amplas, abrangendo a organização de documentos

7 Conforme consta no parecer que acompanha o Plano Orientador de Implantação do Centro de Documentação da Universidade de Brasília, "a palavra 'Arquivo' foi suprimida da denominação original do Centro por considerá-la redundante, pois um Centro de Documentação já pressupõe a existência de um arquivo, além de outros tipos de acervos documentais". 
arquivísticos e museológicos, catalogação de bens históricos, desenvolvimento de pesquisa histórica e difusão cultural.

De um ponto de vista retrospectivo tais objetivos, embora muito pertinentes, eram inviáveis porque precisariam contar com uma estrutura administrativa e de pessoal que jamais o Centro viria a ter. Ademais, atividades tão difusas acabaram por retardar ou dificultar ainda mais a operacionalidade de serviços arquivísticos e a implementação da gestão de documentos, embora se tenha registro de algumas tentativas de realizá-la e de criar um sistema de arquivos. De fato, porém, a maior parte da produção e o fluxo dos documentos resultantes das atividades administrativas e acadêmicas da UnB cresceram alheios à existência da legislação arquivística nacional e à implementação de uma gestão arquivística. Ainda assim, se uma parte da memória das atividades administrativas e acadêmicas da UnB foi preservada, deve-se à iniciativa e aos esforços desse grupo.

A partir de 2008, com a atuação de arquivistas contratados para o quadro permanente da FUB e a instituição da Comissão de Modernização e Reestruturação Administrativa instituída pela Reitoria, foi criado um Grupo de Trabalho, formado por técnicosadministrativos de várias unidades e professores da Faculdade de Ciência da Informação (FCl) para estudar a reestruturação do CEDOC. Uma das mudanças significativas na estrutura do CEDOC ocorreu em 2011 quando a Subsecretaria de Comunicação Administrativa (SCA), então responsável pela função de protocolo da UnB, foi incorporada ao Centro.

Finalmente, a extinção do CEDOC e da SCA e a criação do Arquivo Central (ACE) foram aprovadas pela Resolução do Conselho Universitário no 2, de 19 de fevereiro de 2014, e publicada no Diário oficial da União, em 26 de fevereiro de 2014. Posteriormente foi criado o Sistema de Arquivos da Universidade de Brasília (SAUnB), pela Resolução do Consuni no 39, de 29 de dezembro de 2014, e o Regimento Interno do ACE foi aprovado pela Resolução do Conselho Universitário no 19, de 24 de julho de 2015. O Arquivo Central é, nos termos da Resolução, órgão complementar responsável pela coordenação do Sistema de Arquivos e pela elaboração e implementação da política arquivística da Fundação Universidade de Brasília. O SAUnB é o conjunto de inter-relações de funções e serviços, no âmbito do qual será implementada a política arquivística. O SAUnB é composto pelo Arquivo Central (ACE); a Comissão Permanente de Avaliação de Documentos (CPAD) e os arquivos setoriais da UnB.

A visibilidade e o reconhecimento do ACE no âmbito da comunidade universitária, entretanto, não dependem apenas da sua inserção no organograma da Universidade, embora seja um fator importante para obter as condições adequadas de trabalho e o respaldo perante a comunidade universitária para o cumprimento das normas e implementação dos 
procedimentos arquivísticos. Em 2013, na transição administrativa, a Direção em conjunto com a equipe de arquivistas elaborou um planejamento estratégico ${ }^{8}$ que inclui um plano de ação para a estruturação e o fortalecimento da gestão do ACE e um plano de ação para o gerenciamento de documentos arquivísticos da UnB.

Paralelamente à reorganização do arquivo da UnB, desde 2011 vem sendo conduzido pela Faculdade de Ciência da Informação e Faculdade de Comunicação, em conjunto com outras unidades acadêmicas e unidades de informação da UnB (Biblioteca Central, UnBTV, Secretaria da Comunicação etc.) amplo debate (e ações) sobre a gestão da memória da universidade, envolvendo as diversas áreas de conhecimento e a comunidade arquivística, a fim de propor uma política de informação, documentação e comunicação para a UnB. Buscase, no âmbito deste debate, evidenciar o papel estratégico dos serviços arquivísticos para a qualidade dos serviços da administração, do ensino, da pesquisa e extensão e definir, juntamente com a comunidade universitária, os quadrantes da memória universitária que se pretende preservar.

A implementação da gestão de documentos é, sem dúvida, um grande desafio. Implica em realizar um diagnóstico aprofundado da situação dos arquivos correntes e das massas acumuladas nas unidades administrativas e acadêmicas, inserir mudanças nas rotinas de trabalho, com a aplicação dos planos de classificação e tabelas de temporalidade, realizar treinamentos para os servidores responsáveis pelos arquivos das unidades compreenderem princípios, conceitos e normas relacionados à produção, classificação, avaliação, transferência e recolhimento, sensibilizar continuamente a comunidade universitária sobre a função dos documentos de arquivo e os cuidados que se há de ter com eles.

A UnB, tende ainda, por meio de tratativas com o Arquivo Nacional, a assumir a responsabilidade pela guarda, preservação e acesso aos documentos de caráter permanente da instituição que seriam, a princípio, responsabilidade daquela instituição. Isto significa maior responsabilidade para o ACE, posto que o tratamento da documentação na fase permanente exige um trabalho minucioso de controle físico da documentação e descrição normalizada dos conjuntos documentais para dar acesso a todos os cidadãos interessados.

\footnotetext{
${ }^{8} \mathrm{O}$ termo mais adequado seria planejamento tático, mas como não havia ainda sido elaborado o planejamento estratégico da UnB, optou-se por usar este nome.
} 


\section{Considerações finais}

O processo de expansão das IFES, com a criação de mais cursos e vagas, exige proporcionalmente a expansão da infraestrutura física, administrativa, tecnológica e de pessoal para atender esse crescimento. Os arquivos das universidades, independente do nome formal que tenham - ainda que o nome "arquivo" seja importante para definir bem sua função - precisam acompanhar esse crescimento de forma contínua e padronizada. Precisam também da infraestrutura e do planejamento para realizarem com êxito sua missão.

Há ainda muitas discrepâncias nas condições de atuação nos arquivos das IFES. Algumas universidades conseguiram criar a unidade, mas não tem espaço nem pessoal. Outras têm pessoal e estrutura física, mas não têm respaldo legal. Não há, ainda, arquivistas em todas as universidades, nem cursos de Arquivologia em todas as regiões do país. Faz-se urgente os gestores das universidades atenderem as disposições legais. Criar, manter e dar acesso aos arquivos nas universidades não é direito, é dever.

Faz-se premente atender a essas necessidades porque o trabalho a ser realizado não é simples, nem rápido. Exige estudar a estrutura da universidade, definir prioridades, estabelecer estratégias de organização que dependem não só dos arquivistas, mas de todos os servidores e colaboradores que atuam nas universidades. Cada dia perdido significa um risco maior não só de perda de documentos, mas de perda do contexto em que foram produzidos esses documentos, sem o qual, os documentos de arquivo não podem ser compreendidos integralmente.

O papel dos arquivos das universidades e o de docentes e técnicos atuantes na reinvindicação da instituição plena dos arquivos nas universidades parece ser o de atuar firme - e constantemente - no convencimento da administração superior quanto à importância dos arquivos na tomada de decisões a respeito de rotinas de produção, tramitação, destinação, mudança de suporte e arquivamento de documentos; classificação de documentos sigilosos; definição de adoção de tecnologias de informação e comunicação; aquisição de acervos arquivísticos, entre outros assuntos que se apresentarem.

É fundamental que docentes, arquivistas e demais profissionais da informação estabeleçam diálogo e busquem soluções inovadoras. Afinal, eles trabalham em um local propício para isso, pois a universidade é o locus por excelência da investigação, da invenção, da crítica e da criatividade.

Finalizamos este artigo com mais uma citação de Saramago que, ironicamente, não frequentou a universidade como aluno, mas generosamente refletiu sobre os seus (des)caminhos e conviveu com ela. Diz ele: "mudar não é fazer novas autoestradas, nem estimular avanços que nos proporcionem uma vida cada vez mais fácil, a mudança de que precisamos é de mentalidade" (SARAMAGO, 2013, p.40). 


\section{Referências}

ALVES, Flávia de Freitas. ANPAE. 25 Simpósio Brasileiro de Política e Administração da Educação. Políticas públicas e gestão da educação: construção histórica, debates contemporâneos e novas perspectivas. 26 a 30 de abril de 2011. São Paulo, Brasil. A reforma do Estado nos anos 90 e sua influência na autonomia das universidades federais brasileiras. Disponível em: <http://www.anpae.org.br/simposio2011/cdrom2011/PDFs/trabalhosCompletos/comunicaco esRelatos/0193.pdf>. Acesso em: 28 set. 2014.

BOTTINO, Mariza. Arquivos universitários: repertório bibliográfico preliminar. Arquivo \& Administração, v. 1, n. 2, Rio de Janeiro, jul. /dez. 1998, p. 57-79.

BRASIL. Decreto no50.732, de 6 de junho de 1961.

BRASIL. Lei no12.527, de 18 de novembro de 2011.

BRASIL. Arquivo Nacional. Portaria no92, de 23 de setembro de 201. Disponível em: < http://www.conarq.arquivonacional.gov. br/cgi/cgilua.exe/sys/start.htm?infoid=674\&sid=56> Acesso em: 27 set. 2014.

BRASIL. REUNI. Reestruturação e Expansão das Universidades Federais: diretrizes gerais. Plano de Desenvolvimento da Educação: agosto de 2007. Disponível em: <http://portal.mec.gov.br/sesu/arquivos/pdf/diretrizesreuni.pdf>. Acesso em: 11 jul. 2012.

BRASIL. MINISTÉRIO DA EDUCAÇÃO. Análise sobre a Expansão das Universidades Federais (2003 a 2012). MEC: Brasília, 2012. Disponível em: $<$ https://www.google.com.br/webhp?sourceid=chrome-instant\&ion=1\&espv=2\&ie=UTF8\#q=universidades+federais+no+Brasil+nos+anos+1990?>. Acesso em: 28 set.2014.

FÁVERO, Maria de Lourdes de Albuquerque. A universidade no Brasil: das origens à Reforma Universitária de 1968. EDUCAR, Curitiba, n. 28, 2006, p. 17-36.

MARTINS, Carlos Benedito. O ensino superior brasileiro nos anos 90. São Paulo em Perspectiva, São Paulo, v. 14, n. 1, Jan./Mar. 2000. Disponível em: <http://www.scielo.br/scielo.php?script=sci_arttext\&pid=S0102-88392000000100006>.

Acesso em: 29 set. 2014

MARTINS, Neire do Rossio. Seminário de Arquivos Universitários e Instituições de Pesquisa e Ciência (Abertura). Associação dos Arquivistas Brasileiros. Congresso Brasileiro de Arquivologia: 15: 30 de junho a 04 de julho de 2008, Goiânia, Brasil [recurso eletrônico] / Associação dos Arquivistas Brasileiros, Associação de Arquivologia do Estado de Goiás. Goiânia: AAB: AAG, 2008. Disponível em: <http://www.aag.org.br/anaisxvcba/conteudo/resumos/semiario_arquivos_universitarios/neir e_abertura.pdf>. Acesso em:25 set.2014.

ORTIZ, Renato. Sociedade e cultura. In: SACHS, Ignacy; WILHEIM, Jorge; PINHEIRO, Paulo Sérgio (Orgs.). Brasil: um século de transformações. São Paulo: Companhia das Letras, 2001. 
RIBEIRO, Darcy. Universidade de Brasília: projeto de organização, pronunciamento de educadores e cientistas e Lei $\mathrm{n} . \mathbf{0 3 . 9 9 8}$, de 15 de dezembro de 1961. Brasília: Editora Universidade de Brasília, 1. reimpressão, ed. Especial, 2012.

SARAMAGO, José. Democracia e universidade. Belém: Editora UFPA; Lisboa: Fundação José Saramago, 2013.

VENÂNCIO, Renato. Arquivos universitários no Brasil: esboço de uma cronologia. In: VENÂNCIO, Renato e NASCIMENTO, Adalson (Orgs.). Universidades e arquivos: gestão, ensino e pesquisa. Belo Horizonte: Escola de Ciência da Informação da UFMG, 2012.

UNIVERSIDADE DE BRASÍLIA. CENTRO DE DOCUMENTAÇÃO. Plano Orientador de Implantação do Centro de Documentação da Universidade de Brasília. Brasília: CEDOC, 1988.

Recebido/Recibido/Received: 2015-09 02 Aceitado/Aceptado/Accepted: 2015-10-22 